\title{
Journal of Community Medicine
}

Open Access | Research Article

\section{Smoke exposure following domestic pollution: Prevention and community medicine improvement}

\author{
*Corresponding Author (s): David Baguma, \\ Visiting Professor, Disease Control \& Environmental \\ Health Department, Makerere University, School of \\ Public Health, P.O.Box 7072 Kampala, Uganda \\ Email: baguma.david@yahoo.com \& \\ bagusha2000@yahoo.com
}

Received: Feb 05, 2018

Accepted: Apr 18, 2018

Published Online: Apr 27, 2018

Journal: Journal of Community Medicine

Publisher: MedDocs Publishers LLC

Online edition: http://meddocsonline.org/

Copyright: (C) Baguma D (2018). This Article is distributed under the terms of Creative Commons Attribution 4.0 international License

Keywords: Bush-burning; Weather; Health; Poverty; Rural household; Plants; Water

\section{Introduction}

Living communities are partly affected by smoke exposure for many people worldwide owing to the burning of wood fuel, coal and charcoal. Cooking food items using fuels like biomass can be a health risk not only in low-income countries but also in high- and middle-income countries [1].

The health implication of hazardous air pollution, such as lung diseases are severe, but lack of affordable monitoring devices often prevents the collection of actual data, limiting the revelation of information on associated factors, including the low levels of income, lack of appropriate technology and the inadequacy of community medicine precautionary measures, as well as adequate implementation of government policies.

\section{Abstract}

Objective: Domestic pollution and related impacts are partly from smoke exposure, such as wood fuel smoke, factory smoke, cigarette smoke, motorcycles, and bush burning. The effects of smoke pollution were investigated.

Method: We reviewed literature on potential health risks resulting from smoke pollution occurring in households.

Result: Smoke pollution is linked to lower-respiratory diseases, heart disease, damage to the brain, liver and kidney, bronchitis and pneumonia. Toxic gases in air due to smoke pollution increases the burden of diseases, including plants getting stunted, water scarcity and water drying up, which could exacerbate domestic poverty and lead to the inability to cover community medicine expenses in many countries. The risks partly arise from inadequately ventilated stoves, burning biomass fuels, such as wood fuel, dung or coal, which impact phenomena that influence the accumulation of greenhouse gases, particularly carbon dioxide, and the accompanying weather changes.

Conclusion: The research recommends persistent policy measures that improve community medicine and living environments worldwide.
In some instances, household members using traditional energy facilities, such as three-stone stoves, to carry out domestic chores are affected owing to lack of advanced technologies and exposure to open heat.

Biomass burning in many scenarios is linked to the emission of colloidal particles, dispersed air pollutants in the form of gases, smoke and aerosols. Worldwide, the use of biomass energy, particularly in remote village areas and in urban areas, cannot be avoided as it is crucial for house warming and for cooking food. In such communities, residents' access to modern energy resources is insufficient; while as, biomass fuels are readily available for use [2].

Cooking indoors usually involves inadequate biomass fuel

Cite this article: Baguma D. Smoke exposure following domestic pollution: Prevention and community medicine improvement. J Community Med. 2018; 2: 1006 
combustion, which results in the emission of inhalable Particulate Matter (PM), carbon monoxide and Polycyclic Aromatic Hydrocarbons (PAHs) [1]. Indeed, worldwide the impact of the disease burden is estimated at 3.5 million premature deaths owing partly to ambient air pollution.

Biomass combustion in communities is increasingly becoming recognised as a major contributor to weather changes because of the emission of greenhouse gases. Moreover, biomass combustion emits pollutants such as black carbon, which negatively influences crop yields and also could influence the melting of glaciers and disruption of the monsoon. Knowledge of indoor exposure is, however, inadequate yet a big number of the world population spend substantial amounts of time in-house in many countries.

The present research attempts to contribute information on smoke pollution effects. We reviewed literature published between 2000 and 2014 that considers the potential risks that result from smoke pollution occurring in communities worldwide, to emphasise measures aimed at the reduction of health risks in low-income and middle- or high-income countries.

\section{Materials and methods}

A comprehensive literature review of reports and documents was undertaken between 2015 and 2016 using available sources: [3,4] as used to search other databases [5]. Several keywords were used, including 'household smoke', 'air pollution', 'diseases', 'smoke deaths' and 'stoves'.

Selection criteria included documents that specifically described 'smoke between 2000 and 2014' in the study. Those describing smoke alone (not followed by 'household') as well as those that occurred before 2000 were excluded.

\section{Results}

Although we collected 140 articles and reports, we selected 18 studies. The published documents on PM2.5 and related cook stoves spanned 14 years (2000 to 2014). Crop straws were mainly used in remote village households (Table 1 ).

The present study found that wheat and rice straw were part of the crop straws mainly available for use. The classification of PM2.5 emission data collected was insignificantly different ( $p>0.05)$, partly owing to the small sample sizes. Tree species were used as household indoor fuels. The increased pollutant emissions recorded are documented in a tree species context and fuel moisture.

Wood fuels are classified as wood logs and branches, which produce different emissions $[6,7]$.

The average PM2.5 was significant $(p<0.05)$ for wood logs and branches at $1.8 \pm 1.3 \mathrm{~g} / \mathrm{kg}$ and $2.6 \pm 0.7 \mathrm{~g} / \mathrm{kg}-1$. The study also found the effects of indoor PM2.5 pollution, especially high concentrations during the different seasons (winter). The finding was consistent with those of studies conducted in Asia (Table $1)$. The table shows the findings of the computations $(x \pm s)$ of primary PM2.5 emissions (EF; g kg-1).

\section{Discussion}

The present review reveals that when traditional stoves are replaced, household members can improve their living environments. For instance, the PM2.5 emissions from households burning bituminous coal can be reduced by the use of briquettes. Additionally, the use of biomass can be replaced with the use of efficient cook stoves, such as gasified burners and forced draft stoves, which may reduce hazardous health risks.

The rate of emission in residential households practising wood log burning was higher than that in households that use efficient cook stoves, for instance gasified burners that use pellets. Kerosene was found to be commonly used as household fuel. Additionally, households were found to have poorly constructed ventilated kitchens, which could affect the health of members.

The risks from emissions could also influence climatic scenarios over time. The accumulation of greenhouse gases, such as carbon dioxide, may necessitate strategies to improve current adaptation measures. This finding is consistent with that in several epidemiological studies, which suggest that the effects of smoke from kerosene increases health risks. With regard to women living in rural areas, most women in the review revealed that Improved Charcoal Stoves (ICS) are good compared to traditional charcoal Three-Stone Stove (TCS), considering concerns about handling, emission generation and ease to cook. The impact could reduce health risks associated with eye irritation, lung disease and headache, which relate to other studies [8].

Nevertheless, among old women the use of improved cooking stoves may not be adequate for cooking large amounts of food. For instance, there may be much expense involved in preparing a large quantity of food, and the required funds are not readily available all the time.

Tobacco smoke was also found to be a health risk because burning and smoking tobacco products is linked to heart disease risks, such as stroke, among even non-smoking adults and children. The risks could be middle ear disease and reduced lung function, and asthma in children.

Children are affected by second-hand exposure since when they are developing physically, breathing rates tend to be relatively much high, and since they lack adequate control over their breathing environment and international environmental agreements [9]. The present study relates to findings which indicate that some youth live in households with $100 \%$ smoke-free rules and are not likely to report second-hand exposure

\section{Conclusion}

The present study aimed to contribute information on smoke pollution effects. Literature on potential risks from smoke pollution occurring was reviewed. Inappropriately ventilated kitchens are used, which could impact the health of many exposed individuals. Smoke pollution was linked to lower-respiratory diseases, heart disease, damage to the brain, liver and kidney, bronchitis and pneumonia.

Toxic gases in air due to smoke pollution increase the burden of diseases, including plants getting stunted and drying up, which could exacerbate domestic poverty. Health risks and related impacts result partly from sources, such as wood fire smoke, factory smoke, chimney smoke, cigarette smoke, and exhaust smoke from motor vehicles and motorcycles.

The risks are also partly due to inadequately ventilated stove and the burning of biomass fuels (such as coal), which influence the accumulation of greenhouse gases, particularly carbon dioxide, and the accompanying changes in weathercast scenarios. This research recommends policy suggestions to improve community medicine and living environments worldwide. 


\section{Table}

Table 1: The means and standard derivations $(x \pm s)$ of primary PM2.5 emissions ( $E F ; \mathrm{g} \mathrm{kg}^{-1}$ ), thermal efficiency ( $\eta$; \%) and net caloric values (NCV; $\mathrm{MJ} \mathrm{kg}^{-1}$ ) for different fuel types.

\begin{tabular}{|c|c|c|c|c|c|}
\hline Description & $\mathbf{N}$ & $\mathrm{EF}, \mathrm{kg}^{-1}$ & $\begin{array}{c}\text { NCV, MJ } \\
k^{-1}\end{array}$ & $\eta, \%$ & References \\
\hline Crop straw & 18 & $5.6 \pm 3.1$ & $16 \pm 2$ & $16 \pm 4$ & [10-14] \\
\hline Firewood log & 24 & $1.8 \pm 1.3$ & $18 \pm 1$ & $18 \pm 6$ & {$[6,11,12,14]$} \\
\hline Wood ranches & 5 & $2.6 \pm 0.7$ & $17 \pm 2$ & $14 \pm 1$ & {$[6,11,12,14]$} \\
\hline $\begin{array}{c}\text { Anthracite } \\
\text { chunk }\end{array}$ & 5 & $1.1 \pm 0.4$ & $21 \pm 5$ & $14 \pm 5$ & [13-16] \\
\hline $\begin{array}{l}\text { Bituminous } \\
\text { chunk }\end{array}$ & 32 & $12 \pm 10$ & $28 \pm 4$ & $14 \pm 5$ & [13-16] \\
\hline $\begin{array}{l}\text { Anthracite } \\
\text { briquette }\end{array}$ & 3 & $0.59 \pm 0.58$ & $21 \pm 5$ & $32 \pm 12$ & [13-16] \\
\hline $\begin{array}{l}\text { Bituminous } \\
\text { briquette }\end{array}$ & 26 & $7.1 \pm 4.9$ & $28 \pm 4$ & $32 \pm 12$ & [13-16] \\
\hline $\begin{array}{c}\text { Crop straw } \\
\text { pellet }\end{array}$ & 12 & $2.1 \pm 1.0$ & $14 \pm 1$ & $37 \pm 6$ & {$[6]$} \\
\hline Wood pellet & 20 & $0.85 \pm 0.18$ & $16 \pm 1$ & $29 \pm 6$ & {$[6,17]$} \\
\hline Natural gas & 2 & $0.16 \pm 0.06$ & $51 \pm 2$ & $57 \pm 5$ & [14] \\
\hline LPG & 2 & $0.27 \pm 0.36$ & $49 \pm 2$ & $44 \pm 2$ & [14] \\
\hline
\end{tabular}

Notes: The sample size $(\mathrm{N})$ is the number of available test cycles, for repeated measurements of one fuel stove combination is considered as one.

\section{References}

1. Bonjour $\mathrm{S}$, Adair-Rohani $\mathrm{H}$, Wolf J, Bruce NG, Mehta S, PrüssUstün A, Lahiff M, Rehfuess EA, Mishra V, Smith KR. Solid fuel use for household cooking: country and regional estimates for 1980-2010. Environ Health Per-spect. 2013; 121: 784-790.

2. Klasen EM, Wills B, Naithani N, Gilman RH, Tielsch JM, Chiang M, Khatry S, Patrick N, Breysse, Menya D, Apaka C, Carter EJ, Sherman CBJ, Miranda J, Checkley W. COCINAS Trial Working Group. Low correlation between household carbonmonoxide and particulate matter concentrations from biomass-related pollution in three resource-poor settings. Environmental Research. 2015; 142: 424-431.

3. Scopus and Science Direct. The 30 days access for reviewers to references, abstracts, and full-text articles in Scopus and ScienceDirect for 30 days, activated after use of EES login details to register. 2015.
4. Google. 2015.

5. Kouadio IK, Aljunid S, Kamigaki T, Hammad K, Oshitani H. Infectious diseases following natural disasters: prevention and control measures. Expert Review of Anti-infective Therapy. 2012; 10: 95-104.

6. Shen G, Wei S, Zhang Y, Min Y, Wang B, Wang R, et al. Emission factors, size distributions and emission inventories of carbonaceous particulate matter from residential wood combustion in rural China. Environ Sci Technol. 2012; 46: 4207-4214.

7. Edwards R, Smith K, Zhang J, Ma Y. Implications of changes in household stoves and fuel use in China. Energ Policy. 2004; 32: 395-441.

8. Shen G, Tao S, Wei S, Zhang Y, Wang R, Wang B, et al. Reductions in emissions of carbonaceous particulate matter and polycyclic aromatic hydrocarbons from combustion of biomass pellets in comparison with raw fuel burning. Environ Sci Technol. 2012; 46: 6409-6416.

9. Baguma D. Public health safety and environment in inadequate hospital and healthcare settings: a review. Public Health. 2017; 144: 23-31.

10. Cao G, Zhang X, Gong S, Zheng F. Investigation on emission factors of particulate matter and gaseous pollutants from crop residue burning. J Environ Sci. 2008; 20: 50-55.

11. Li X, Duan X, Wang S, Duan L, Guo X, Yi H, et al. Emission characteristics of particulate matter from household biofuel combustion in China. Energy Fuel. 2007; 21: 845-851.

12. Li X, Wang S, Duan L, Hao J, Nie Y. Carbonaceous aerosol emissions from household biofuel combustion in China. Environ. Sci Technol. 2009; 43: 6076-6081.

13. Shen G, Yang Y, Wang W, Tao S, Zhu C, Min Y, et al. Emission factors of particulate matter and elemental carbon for crop residues and coals burned in typical household stoves in China. Environ. Sci. Technol. 2010; 44: 7157-7162.

14. Zhang J, Smith KR, Ma Y, Ye S, Jiang F, Qi W, et al. Greenhouse gases and other airborne pollutants from household stoves in China: a database for emission factors. Atmos Environ. 2000; 34: 4537-4549.

15. Liu Y, Zhang Y, Wei Y, Dou H, Gu D, Zeng L, et al. Measurement of emission factors of carbonaceous aerosols from residential coal combustion. Acta Sci Circumstantiae. 2007; 27: 1409-1416.

16. Zhang Y, Schauer J, Zhang Y, Zeng L, Wei Y, Liu Y, et al. Characteristics of particulate carbon emissions from real-world Chinese coal combustion. Environ Sci Technol. 2008; 42: 5068-5073.

17. Chafe ZA, Brauer M, Klimont Z, VanDingenen R, Mehta S, Rao S, Riahi K, Dentener F, Smith KR. Household cooking with solid fuels contributes to ambientPM2.5 air pollution and the burden of disease. Environ. Health Perspect. 2014; 122: 1314-1320. 